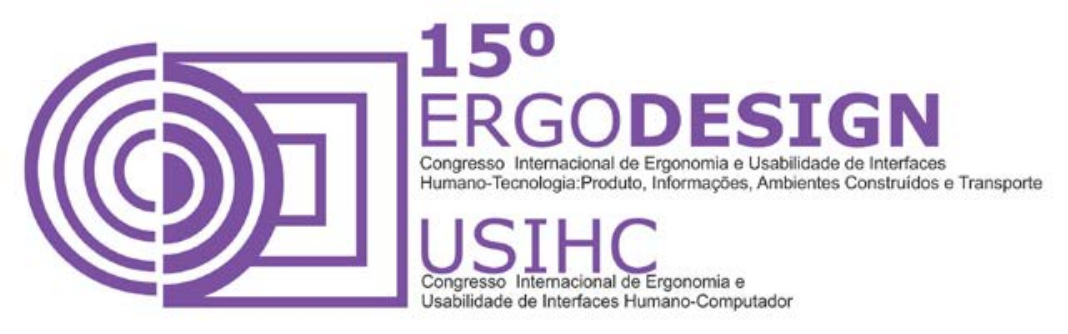

\title{
ERGONOMIA: CONFORTO TÊXTIL NO VESTUÁRIO DO IDOSO
}

\section{ERGONONICS: TEXTILE COMFORT FOR ELDERLY CLOTHES}

\author{
VIANNA, Claudia (1) \\ QUARESMA, Manuela (2)
}

(1) Laboratório de Ergodesign e Usabilidade de Interfaces da PUC-Rio (LEUI), Mestranda em Design

E-mail: claudiammvianna@hotmail.com

(2) Laboratório de Ergodesign e Usabilidade de Interfaces da PUC-Rio (LEUI), Doutora em Design

E-mail: mquaresma@puc-rio.br 


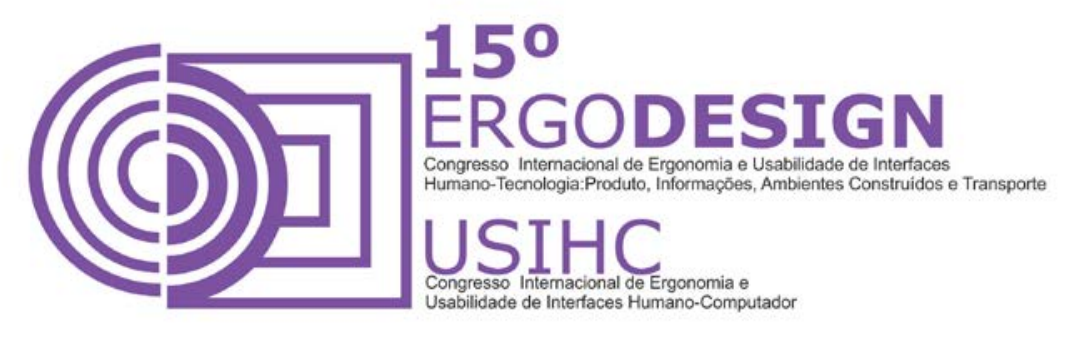

\title{
RESUMO
}

O presente artigo trata da relação do conforto têxtil com o vestuário para idosos. Com o envelhecimento, e as transformações ocorrentes no corpo torna-se necessário que os designers de moda conheçam os tecidos existente no mercado, para que desenvolvam o vestuário adequado, que associados as novas tecnologias possam trazer mais conforto, satisfação e bem estar para a terceira idade.

Palavras-chave: Conforto Têxtil; Vestuário; Idoso; Design de Moda.

\begin{abstract}
This article deals with the relationship of the textile comfort with clothing for the elderly. With aging, and the occurring changes in the body becomes necessary for fashion designers know the existing fabrics on the market, to develop the appropriate clothing, which associated new technologies can bring more comfort, satisfaction and well-being for the seniors.
\end{abstract}

Keywords: Textile Comfort; Clothing; Elderly; Fashion Design.

\section{INTRODUÇÃO}

O envelhecimento da população está acontecendo em todas as partes do mundo e em países em diversos níveis de desenvolvimento. O envelhecimento é uma conquista do desenvolvimento, sendo uma das maiores conquistas da humanidade (ONU, 2012).

Segundo relatório da Organização das Nações Unidas (ONU, 2012), a população mundial deve atingir 9,6 bilhões em 2050. Já em relação à expectativa de vida, a previsão é de que a média de idade seja de 76 anos entre 2045 e 2050 e 82 anos entre 2095 e 2100 . Até o final do século pessoas de países desenvolvidos poderão alcançar, em média, 89 anos e os em desenvolvimento, 81 anos. Portanto o fenômeno do envelhecimento não deve ser ignorado. Uma em cada nove pessoas no mundo tem 60 anos ou mais e a expectativa é de que uma a cada cinco pessoas ultrapassem essa idade por volta do ano de 2050.

Mundialmente as mulheres idosas constituem a maioria entre os idosos, pois para cada 100 mulheres com 60 anos ou mais, existem 84 homens. Já para cada grupo de 100 mulheres com

80 anos ou mais, existem somente 61 homens. Conforme o relatório Envelhecimento no Século XXI: Celebração e Desafio, publicado em 2012 pelo Fundo de População das Nações Unidas (UFNPA), o envelhecimento atinge de formas diferentes entre os homens e as mulheres. Dependendo da vida que levam, os recursos disponíveis e as oportunidades, esses homens e mulheres não devem ser citados como uma categoria única, pois apresentam características diversas, como idade, educação, renda e saúde. É preciso que os idosos sejam tratados de acordo com essas especificidades e de maneira diferente.

Com base nos dados acima em que a grande maioria dos idosos são mulheres, muitas inseridas socialmente e profissionalmente, percebe-se um novo nicho de mercado para 


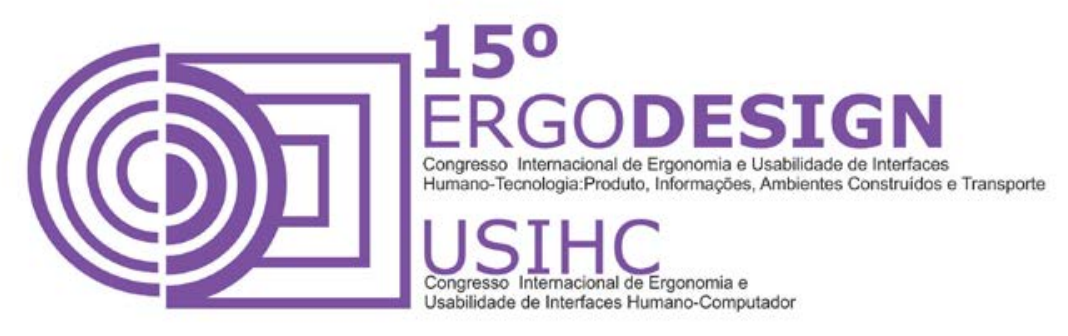

comércio de vestuário. Para Ballstaedt (2007), pesquisas revelaram um segmento pouco explorado, com consumidoras que têm comportamentos, estilos de vida e necessidades específicas. Portanto torna-se relevante conhecer quais são essas necessidades em relação ao vestuário para o maior conforto, segurança e bem estar dessa nova idosa.

Para Menegucci e Santos Filho (2010) são poucas as pesquisas de produtos de vestuários para a população idosa, visto que as empresas não focam nestes usuários. As indústrias e confecções nem sempre utilizam os princípios da ergonomia para o desenvolvimento das roupas. A importância do estudo da ergonomia é fundamental para a confecção de vestuários, para proporcionar conforto, proteção, satisfação e bem estar aos idosos.

Para lida (2005), os ergonomistas devem analisar o trabalho de forma global, contemplando os aspectos físicos, cognitivos, sociais, organizacionais, ambientais e outros. Para Martins e Lopes (2009) os objetivos básicos da ergonomia visam projetar produtos que tragam segurança, satisfação e saúde, reduzindo o estresse, erros e acidentes. Concluem que o vestuário também deve ser adaptado aos usuários, trazendo conforto, mobilidade e segurança, e que antes de qualquer relação dos usuários com o entorno eles se relacionam com suas próprias roupas. Entretanto é preciso que os designers de moda se apropriem deste conhecimento para agregar os valores necessários ao desenvolvimento de vestuário para idosos. O conforto e proteção do vestuário devem ser analisados a partir das ofertas têxteis apresentadas no mercado. Os tecidos são fundamentais para promoverem conforto, saúde, proteção, usabilidade e segurança.

O vestuário é considerado a segunda pele do homem segundo Hollander (1996) apud Martins (2008), além da estética tem a função de proteger, portanto, o conforto deve estar sempre associado ao produto têxtil.

\section{CONFORTO}

O envelhecimento é um processo natural que reflete uma fase da vida do ser humano, em que começam as mudanças físicas, cognitivas e sociais. Dentre as várias transformações que ocorrem com o corpo do idoso, a diminuição da estatura, flexibilidade, perda de massa muscular, ressecamento e perda da elasticidade da pele, devem ser pensados no desenvolvimento do vestuário, tanto na modelagem como na escolha do tecido.

A relação do vestuário com o usuário não deve ser apenas técnica. Gonçalves e Lopes (2007) relatam que "inerente à qualidade do produto, o conforto e a estética são aspectos exigidos cada vez mais" pela demanda do mercado. A roupa fica em constante contato com o corpo.

"O conceito de conforto, normalmente esta ligado ao ambiente térmico. Em relação ao vestuário pode ser verificada a resistência térmica, a resistência ao vapor de água, as condições climáticas e o nível de atividade física do indivíduo." (BROEGA e SILVA, 2007). Para os autores o conforto do vestuário pode ser divido em quatro aspectos conforme a tabela 1:

Tabela 1 - Aspectos fundamentais para o conforto total do vestuário (BROEGA e SILVA, 2007) 


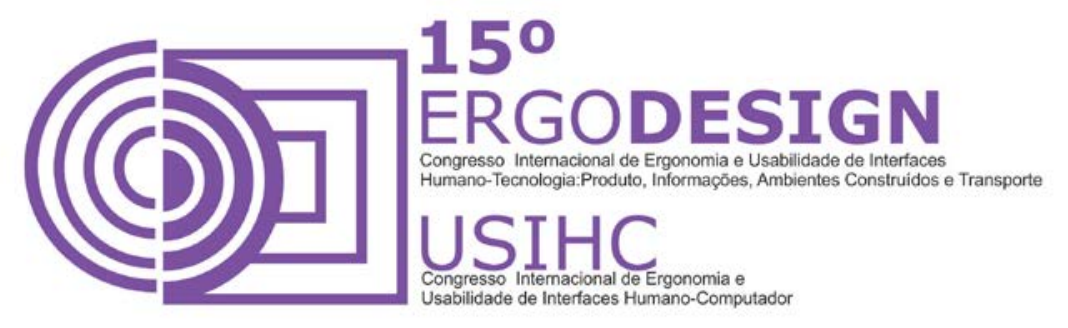

\begin{tabular}{|l|l|}
\hline Conforto termofisiológico & $\begin{array}{l}\text { Estado térmico e de umidade à superficie da pele que } \\
\text { envolve a transferência de calor e de vapor de água } \\
\text { através dos materiais têxteis ou do vestuário }\end{array}$ \\
\hline $\begin{array}{l}\text { Conforto sensorial de } \\
\text { "toque" }\end{array}$ & $\begin{array}{l}\text { Conjunto de várias sensações neurais, quando um tecido } \\
\text { entra em contato com a pele. }\end{array}$ \\
\hline Conforto ergonômico & $\begin{array}{l}\text { Capacidade que uma peça de vestuário tem de "vestir } \\
\text { bem" e de permitir a liberdade dos movimentos do corpo. }\end{array}$ \\
\hline Conforto psico-estético & $\begin{array}{l}\text { Percepção subjetiva da avaliação estética, com base na } \\
\text { visão, toque, audição e olfato, que contribuem para o bem } \\
\text { estar do usuário. }\end{array}$ \\
\hline
\end{tabular}

O conforto térmico tem relação com as sensações de calor e frio, exigindo tecidos que proporcionem o bem estar através de suas características naturais ou tecnológicas como os fios de superfícies irregulares facilitando a circulação do ar. O conforto sensorial de "toque" esta relacionado com o a maciez do tecido que é resultado da sua composição. Pelo fato do idoso ter a pele mais ressecada, o "toque" do tecido é fundamental para a sua usabilidade podendo evitar irritações na pele. Em relação ao conforto psico-estético o idoso vai perceber o tipo de material têxtil, a conformação da roupa no corpo, a escolha das cores e também o odor das roupas usadas. O conforto ergonômico engloba todas as sensações acima, que agregadas à modelagem e confecção do vestuário adequada à nova configuração do corpo do idoso, permitem o bem estar e a liberdade dos movimentos.

Goldman (2005) apud Menegucci e Santos Filho (2010) ressalta ainda quatro quesitos do vestuário relacionados ao conforto, que são conhecidas como os quatro "Fs" conforme a tabela 2.

Tabela 2 - Atribuições relacionadas ao conforto do vestuário (Goldman (2005) apud Menegucci e Santos Filho (2010)

\begin{tabular}{|l|l|}
\hline Estilo (Fashion) & $\begin{array}{l}\text { Adequação do vestuário às tendências de moda e estilo } \\
\text { em determinada época }\end{array}$ \\
\hline Toque (Feel) & Sensação tátil quando a roupa é tocada pelo usuário \\
\hline
\end{tabular}




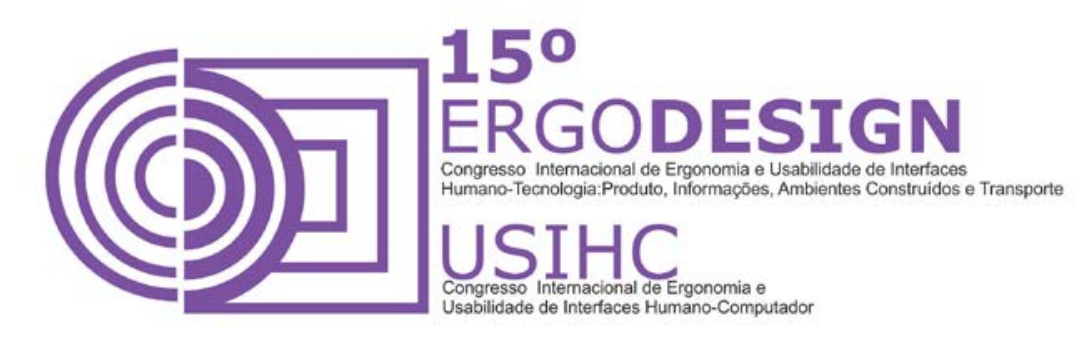

\begin{tabular}{|l|l|}
\hline $\begin{array}{l}\text { Caimento (Fit) } \\
\text { [sic] }\end{array}$ & Ajuste adequado ao corpo sem restringir os movimentos \\
\hline Funcionalidade (Function) & Equilibrio entre a função térmica e mecânica da roupa \\
\hline
\end{tabular}

"O vestuário é uma barreira térmica entre o corpo humano e o seu ambiente. Um dos papeis do vestuário é manter o organismo num estado térmico confortável, qualquer que seja o ambiente exterior." (BROEGA e SILVA 2010). O Conforto se relaciona com o usuário nas questões da modelagem, do modelo estético da roupa, dos aspectos ergonômicos de vestir e desvestir, e do tecido apropriado para as necessidades do idoso.

\section{TECIDOS E TECNOLOGIA TÊXTIL}

Os designers devem conhecer bem os tecidos, pois deles dependem o sucesso da roupa, que vai definir o caimento e a silhueta. Para a escolha do tecido é preciso pensar na estética, que inclui a aparência e o toque, a cor, a estampa ou a textura. (SORGER e UDALE, 2009).

Com a necessidade dos profissionais da moda atender aos consumidores, as indústrias têxteis produtoras de fibras sintéticas procuram desenvolver sempre novas fibras. Com as novas tecnologias as empresas já desenvolvem um grande número de tecidos destinados às diversas necessidades, tanto em relação a uniformes, resistentes e adequados a altas temperaturas, como para esportes e vestuários em geral. Estudos estão sendo realizados para substituir a base das fibras sintéticas de petróleo para materiais biológicos renováveis e biodegradáveis, que têm o mesmo comportamento das fibras naturais (biodegradáveis e recicláveis), com o mesmo desempenho das derivadas do petróleo (FRINGS, 2012).

Segundo Bartels (2011) apud McCann e Bryson (2014) as roupas devem ter conforto, controle da umidade, conforto ergonômico (facilidade de movimento/ajuste próprio e também conforto psicológico (aparência, estar na moda). Os mais idosos, que cresceram vestindo fibras naturais continuam, muitas vezes, preferindo elas do que as fibras sintéticas. "Os requisitos de conforto, ajuste, desempenho, durabilidade e facilidade de cuidados especiais são necessários para todos os consumidores, em especial os da terceira idade" (HILBBERT, 2014).

O algodão e o linho são as fibras naturais mais antigas. Segundo Chataignier (2006) o algodão é mais usado pela população mundial e também a mais resistente.(Figura 1) 

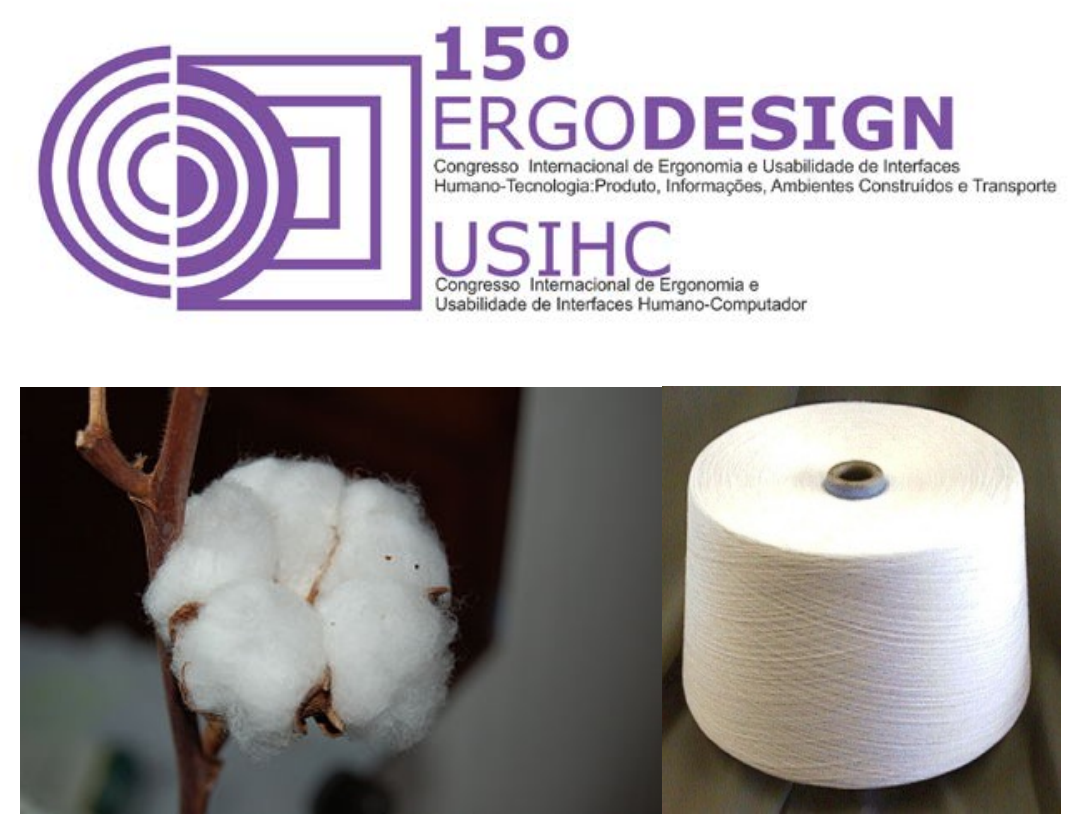

Figura 1.0 algodão é a fibra têxtil mais consumida no mundo (http://www.fashionbubbles.com/historia-da-moda/algodao-a-fibra-mais-usada-no-mundo/2 http://pt.wikipedia.org/wiki/Fibra_t\%C3\%AAxtil)

Esta característica de resistência possibilita a produção de uniformes de trabalho e ainda é a principal matéria prima do jeans. "A preocupação com a ecologia faz com que alguns produtos químicos sejam evitados, algumas marcas estão incluindo em suas coleções, peças de algodão puro. Estes tipos de tecido estão relacionados com o conforto e são fáceis de lavar "(PEZZOLO, 2007). Mas também podem reter a umidade, demorando para secar causando sensação de frio quando molhado, podendo afetar a saúde do idoso.

Já o linho é a fibra mais ecológica, pois não são usados fertilizantes químicos. Tanto para Chataignier (2006) como para Pezzolo (2007) o linho agrega conforto, estética e funcionalidade; de fácil lavagem, secagem rápida, tem elasticidade e resistência. Não atrai traças, cupo, ou mofo. Pezzolo (2007) diz ainda que o linho é também antialérgico e antibactericida. Propriedades que tornam o uso adequado a terceira idade, entretanto, é considerado um tecido nobre, pelo preço alto no mercado. Apropriado para a confeção de camisas, calças, vestidos, saias e blusas.

A lã é a fibra natural animal mais utilizada, serve de proteção contra o frio, e também é associada ao aconchego. Ajuda a manter a temperatura térmica do corpo do idoso. Segundo Pezzolo (2007) a lã fria pode ser usada em temperaturas mais altas, garantindo proteção e transpiração natural, quanto mais fina, mas variável o seu uso. As peças de vestuário de lã são pesadas, principalmente quando molhadas. Alguns tipos de lã têm as fibras mais finas, que transmitem aspecto mais elegante e ainda podem ser lavadas em máquina caseiras, facilitando o dia a dia do usuário.

A seda é considerada a fibra natural mais forte, com grande elasticidade e com toque agradável. Segundo Pezzolo (2007) a seda é a única fibra natural que tem formato de filamento contínuo. "Também chamada de seda pura, é muito macia, quando dobrada amarrota-se, diferente das sedas de fibras sintéticas, que não amarrotam" (CHATAINGNIER, 2007). Para McCann e Bryson (2014) a seda tem grande capacidade de absorção tornando-se confortável para usar em qualquer temperatura, protege do calor e do frio, mantendo o ar quente em contato com a pele. Desta forma a seda é uma fibra ideal para camadas de base térmica, forros, principalmente para peles sensíveis como a dos idosos, é também hipoalergênico 


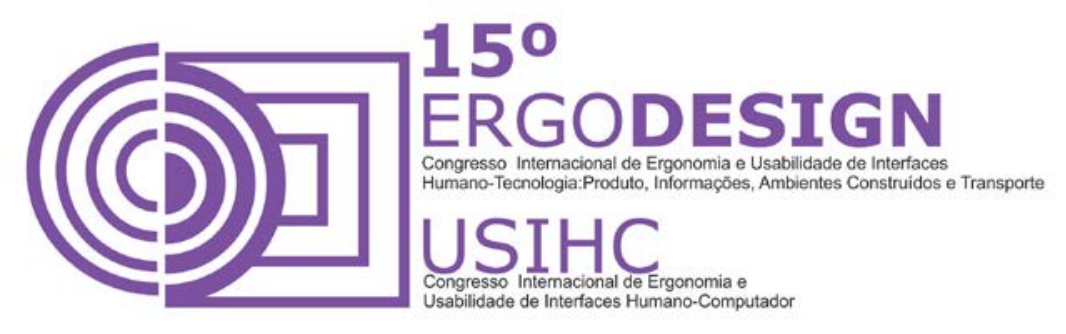

evitando irritações na pele. Usada para confecção de camisas, blusas, vestidos e saias. O custo da seda pura dificulta atender o idoso que, em geral, perde poder aquisitivo com o passar dos anos.

Com as inovações tecnológicas houve um grande avanço em relação às fibras para tecidos, a primeira fibra produzida sinteticamente foi a poliamida, fibra fina, resistente e tão elegante quanto a seda. "As fibras sintéticas não são consideradas simples alternativas às fibras naturais, tem alta funcionalidade com propriedades específicas, onde suas características de leveza em combinação com resistência à tração e resistência à abrasão são valorizadas" (McCAMM e BRYSON, 2014). As mais utilizadas além da poliamida, são o poliéster, o acrílico, o elastano e o polipropileno.

Para Frings (2012), as fibras sintéticas podem ser misturadas com suas próprias fibras ou com as fibras naturais. Aproveitando a melhor qualidade de cada uma delas podem fornecer tecidos com características próprias. Entretanto as fibras artificiais podem produzir também a textura das fibras naturais e obter efeitos estéticos e melhor desempenho.

O poliéster é a fibra artificial mais usada, ela é resistente a vincos e amassados. Pode ser usado misturado ao algodão, viscose, náilon, linho ou lã. O resultado desses novos tecidos servem para a fabricação de artigos como camisas, vestidos, calças e ternos. É uma das fibras mais baratas, muito resistente, de fácil manutenção, porém absorvem muito calor, podendo causar irritação na pele. Portanto não é recomendada para ser usada em roupas para idosos. Entretanto para Romero et al.(1995) o consumo do poliéster deverá crescer, pelo baixo custo e aos melhoramentos tecnológicos que podem fazer com que se aproxime cada vez mais do algodão

O acrílico pode ser um bom substituto para a lã, proporciona calor, leveza e maciez e é muito usado na confecção de malhas, casacos, meias, gorros e artigos infantis. Bom isolante térmico o acrílico não amassa e, com secagem rápida, tem um toque agradável e não causa alergia. Desta forma, é aconselhado o seu uso para o vestuário da terceira idade, apesar dos custos altos para a sua produção. (Figura 2)

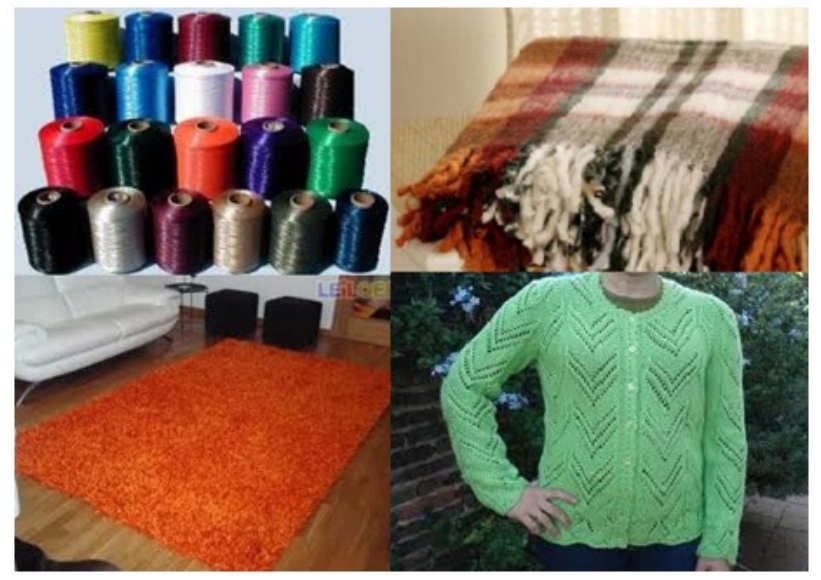

Figura 2: Indústria têxtil: Fibras Acrílicas (http://www.quimlab.com.br/pesquisa.htm) 


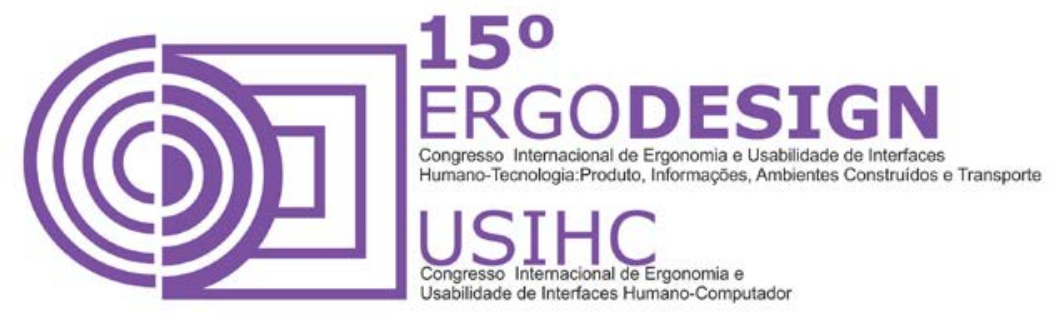

O elastano misturado a algumas fibras pode produzir uma maior elasticidade, Sua principal função é trazer elasticidade aos tecidos como malha e tecidos planos para a confecção de peças que aderem ao corpo sem prejudicar os movimentos. Muito utilizada em roupas de praia, lingerie, roupas esportista, meias trazendo mais conforto ao usuário.

As fibras derivadas da polpa da madeira, fibras celulósicas são as que ficam mais perto das fibras naturais em relação ao toque e caimento. A viscose foi a primeira desenvolvida e serve para confeccionar vestidos, blusas, saias, que com suas características são adequadas ao vestuário para idosos. O bambu, que tem o processo de fabricação semelhante à viscose, também pode ser utilizado no vestuário para idosos. Leve e maleável, a fibra do bambu se mistura bem com o algodão, com a elastano e com a seda. Já o acetato, muito usado em roupas de festa, tem o toque semelhante a seda e também traz um bom caimento.

"Com o surgimento dos "novos tecidos que não encolhem nem amarrotam e oferecem vantagens: cores que não desbotam, conforto, fácil lavagem e secagem rápida, capacidade de aquecer no frio e de refrescar no calor e de acelerar a troca térmica: capacidade de retirar da parte interna da roupa,... o que mantém o corpo confortavelmente seco... além de propriedades antimicrobiana, antiestática", (PEZZOLO, 2007) além da propriedade antibactericida que previnem irritações e infecções e proteção contra os raios UV, proporcionando uma melhor solução para a confecção de vestuário para idoso.

Os tecidos tecnológicos são tecidos de alta qualidade, com funções especificas e valorizam as criações dos designers, podendo trazer mais conforto e proteção aos usuários. As roupas são agradáveis de vestir, são resistentes ao calor e, segundo Pezzolo (2007), os tecidos conhecidos como tecidos inteligentes podem ter efeito antiestresse, medir a pulsação e pressão arterial. No contexto esportivo, esses tecidos melhoram o desempenho dos atletas, com suas inovações e também estão presentes na moda do dia a dia.

As indústrias têxteis buscam integrar a moda com a tecnologia, trazendo conforto e benefícios para os usuários. Tecidos tecnológicos são desenvolvidos com grande variedade de cores, não perdem a funcionalidade durante as lavagens, com toque suave, mantêm o equilíbrio térmico e ainda agregam proteção contra os raios solares. Segundo Pezzolo (2007) a Rhodia lançou o primeiro fio bacteriostático, que resultou em um tecido com as mesmas propriedades da poliamida com a função bacteriostática. Esses tecidos inibem o crescimento das bactérias que causam odor, e não deixam que elas migrem para o usuário, permitindo a não alteração do equilíbrio de sua flora bacteriana. Todas estas características são altamente recomendáveis para o uso do vestuário de idosos, que com o decorrer do tempo, necessitam além de conforto e usabilidade, segurança em relação à saúde. Proteger a pele e interagir com as roupas através dos tecidos especiais proporciona aos idosos uma melhor qualidade de vida.

\section{CONSIDERAÇÕES FINAIS}

O conforto têxtil para o vestuário de idosos esta ligado ao planejamento e aprofundamento da interação entre moda e tecnologia. Esse novo nicho e sua relação com o mercado vai exigir

conhecimentos e experiências diversas no que se refere a materiais tradicionais, novos e em fase de estudo, tendo como objetivo maior o conforto em todos os seus aspectos. 


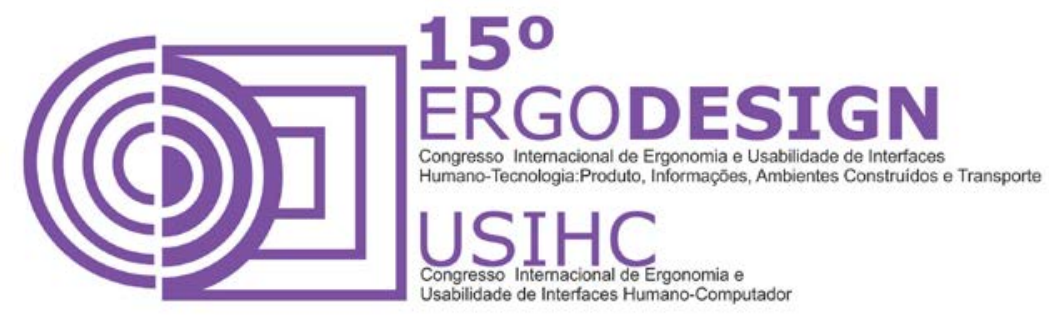

O fenômeno do envelhecimento deve ser pensado sempre no sentido de ampliar e entender essa rede de complexidade que o momento atual apresenta. Nesse sentido este artigo faz um recorte dentro dessa complexidade mostrando a questão da relação idoso-vestuário inserindo a tecnologia, não deixando de levar em conta as questões diversas que caracterizam o idoso em geral que deve ser tratado a partir de suas especificidades e não como categoria única.

Os designers devem se apropriar de conhecimentos em relação aos materiais que vão usar, tanto em relação a tecnologia como nos requisitos básicos para o desenvolvimento de uma roupa confortável. A segunda pele do ser humano exige conforto térmico, físico, sensorial, ergonômico, psicológico e estético e, também, todas as atribuições relacionadas ao conforto com o vestuário como estilo, toque, ajuste e funcionalidade.

O conforto em relação ao vestuário poderá crescer ainda mais se houver empreendimentos voltados para o desenvolvimento da indústria têxtil. Existe a necessidade de criar uma segunda pele confortável para esses novos idosos contemporâneos que vivem e viverão mais, fazendose necessário a integração entre pesquisadores de moda com os profissionais da indústria têxtil. É preciso avançar mais, conhecer profundamente esse novo universo para trazer benefícios que poderão ser de grande valor para o conforto e a segurança dos idosos.

\section{REFERÊNCIAS BIBLIOGRÁFICAS}

BALLSTAEDT, Ana Luiza Maia Pederneiras. Comportamento e estilo de vida da população idosa e seu poder de consumo. Buenos Aires: II Encontro Latino americano de Diseño. Facultad de Desiño y Comunicación, 2007.

BROEGA, Ana Cristina e SILVA, Maria Elisabete Cabeço. O conforto total do vestuário: design para os cinco sentidos. Buenos Aires: V Encuentro Latinoamericano de Deseño "Deseño em Palermo". Universidade de Palermo, 2010.

GONÇALVES, Eliana e LOPES, Luciana Dornbusch. Ergonomia do vestuário: conceito de conforto como valor agregado ao produto de moda. Buenos Aires: II Encontro Latino americano de Diseño. Facultad de Desiño y Comunicación, 2007.

FRINGS, Gini Stephens. Moda: do conceito ao consumidor. Porto Alegre: Bookman, 2012.

MCCANN, Jane e BRYSON, David. Textile-led design for the active ageing population. Cambridge: Elsevier, 2014.

IIDA, Itiro. Ergonomia - Projeto e Produção. 2ª ed. São Paulo: Edgard Blucher, 2005.

MARTINS, Suzana Barreto, Ergonomia e moda: repensando a segunda pele. In: Pires, Dorotéia Baduy (org.) Design de moda, olhares diversos. São Paulo: Estação da Letras e Cores Editora, 2008.

MENEGUECCI, Franciele e SANTOS FILHO, Abílio Garcia. Proteção e conforto: a relação entre os tecidos e o design ergonômico do vestuário para idosos. In: CONGRESSO BRASILEIRO DE PESQUISA E DESENVOLVIMENTO EM DESIGN (9, 2010, São Paulo).

CHATAIGNIER, Gilda. Fio a fio: tecidos, moda e linguagem. São Paulo: Estação das Letras Editoras, 2006.

PEZZOLO, Dinah Bueno. Tecidos: histórias, tramas, tipos e usos. São Paulo: Senac, 2013.

SORGE, Richard e UDALE, Jenny. Fundamentos de design de moda. Porto Alegre: Bookman, 2009. 